\title{
Upaya Preventif Tingkat Keparahan Penyakit Diabetes Mellitus dengan Diet dan Olahraga serta Mengenali Komplikasi Awal di Mata
}

\author{
Preventive Efforts on the Severity of Diabetes Mellitus with Diet and Exercise as well as \\ Recognizing Early Complications in the Eyes \\ ${ }^{1 *}$ Nur Shani Meida, ${ }^{2)}$ Yunani Setyandriana, ${ }^{3)}$ Ika Setyawati, ${ }^{4)}$ Refi Nurcholis \\ ${ }^{1,2}$ Bagian Mata Fakultas Kedokteran dan Ilmu Kesehatan, Universitas Muhammadiyah Yogyakarta \\ ${ }^{3)}$ Bagian Biokimia Fakultas Kedokteran dan Ilmu Kesehatan, Universitas Muhammadiyah Yogyakarta \\ ${ }^{4)}$ Mahasiswa Pendidikan Dokter, Fakultas Kedokteran dan Ilmu Kesehatan, Universitas Muhammadiyah \\ Yogyakarta \\ J1. Brawijaya, Geblagan, Tamantirto, Kec. Kasihan, Yogyakarta, Daerah Istimewa Yogyakarta 55183
}

*email: nurshani_meida@yahoo.com

DOI:

10.30595/jppm.v5i1.9335

Histori Artikel:

Diajukan:

$30 / 12 / 2020$

Diterima:

$10 / 01 / 2022$

Diterbitkan:

$18 / 02 / 2022$

\begin{abstract}
ABSTRAK
Kasus penyakit degeneratif/kronis cukup banyak terutama Diabetes Mellitus (DM). Penyakit DM ini dapat mengakibatkan berbagai komplikasi termasuk komplikasi di mata. Keterlambatan deteksi dini komplikasi di mata akibat penyakit DM tentunya dapat menyebabkan keadaan yang semakin parah dan akan menambah beban biaya bagi penderita serta dapat menimbulkan disabilitas. Peran kader sangat penting dalam pencegahan prevalensi DM tersebut. Kegiatan ini bertujuan untuk diseminasi informasi dan peningkatan pengetahuan masyarakat dan kader dusun Watu tentang penyakit DM serta melatih para kader agar dapat melakukan pengukuran kadar gula darah. Pelaksanaan kegiatan dengan memberikan pendidikan kesehatan secara online dalam bentuk webinar dengan aplikasi Zoom Meeting. Kegiatan pendidikan kesehatan dimulai dengan pretes kemudian sesi pemaparan materi dan diakhiri sesi postes untuk mengukur keberhasilan kegiatan dan tingkat pengetahuan peserta. Kegiatan sesi praktik pengukuran gula darah dilaksanakan secara tatap muka khusus bagi kader Dusun Watu. Kegiatan webinar ini diikuti oleh 103 peserta yang mengikuti kegiatan secara penuh dari awal, pretes sampai dengan selesai termasuk postes. Terdapat peningkatan nilai postes dibandingkan nilai pretes (92,32\%). Seluruh kader dapat melakukan pemeriksaan kadar gula darah (100\%). Kegiatan pengabdian ini telah meningkatkan pengetahuan masyarakat tentang DM dan pencegahan komplikasi di mata serta serta kader dapat melakukan pengukuran kadar gula darah secara mandiri.
\end{abstract}

Kata kunci: Diabetes; Mellitus; Kader; Komplikasi di Mata

\begin{abstract}
There are quite a lot of degenerative diseases, including Diabetes Mellitus (DM). Diabetes Mellitus can lead to various complications including complications in the eye. Delay in early detection of complications in the eye due to DM can get worsen, increase the cost burden for sufferers and disabilities. The role of cadres is very important in preventing the prevalence of DM. This activity aims to disseminate information and increase the knowledge of the community and Watu hamlet cadres about DM disease and train cadres to measure blood sugar levels. Health education are carried out online in the form of webinars with the Zoom Meeting application. Health education begin with a pretest, then a material presentation session and end with a post-test to measure the success of the activity and the level of knowledge of the participants. The practice of measuring
\end{abstract}


Nur Shani Meida, Yunani Setyandriana, Ika Setyawati, Refi Nurcholis

Upaya Preventif Tingkat Keparahan Penyakit Diabetes Mellitus dengan Diet dan Olahraga serta Mengenali Komplikasi Awal di Mata

blood sugar is carried out face-to-face especially for the cadres of Watu Hamlet. There is an increase in the post-test score compared to the pre-test score (92.32\%). All cadres can check blood sugar (100\%). There is an increase in knowledge about DM, the prevention of complications in the eye and cadres can measure blood sugar independently.

Keywords: Diabetes; Mellitus; Cadre; Complications in the Eye

\section{PENDAHULUAN}

Diabetes Mellitus (DM) merupakan salah satu penyakit degeneratif dengan prevalensi tinggi di Indonesia (Perkeni, 2011). Tahun 2018, prevalensi DM pada usia > 15 tahun semakin meningkat $(10,9 \%)$ dan di tahun 2013 sebanyak 1,6\% (Riskesdas, 2008). Indonesia menempati urutan ke-4 dengan prevalensi DM tinggi setelah negara India, China, dan Amerika. Tahun 2000 terdapat penderita DM sekitar 8,4 juta dan diperkirakan tahun 2030 akan meningkat menjadi 21,3 juta. (Khaled Ahmad., et al., 2010).

Penyakit DM dapat menimbulkan beberapa komplikasi di dalam tubuh (Vasudev Anand, P. dan Sridhar, G., 2018). Menurut Vieira-Potter J V et al. tahun 2016 dan Zhao YX et al. tahun 2017 bahwa DM dapat menyebabkan komplikasi di bidang mata dan menjadi faktor risiko beberapa penyakit mata seperti retinopati diabetik, katarak, glaukoma dan lain lain yang pada tahap akhir dapat menimbulkan kebutaan.

World Health Organization (WHO) tahun 2007 melaporkan terdapat lebih dari 7 juta orang menderita buta setiap tahun. Sampai saat ini terdapat 180 juta orang di seluruh dunia mengalami gangguan penglihatan dan 40-45 juta menderita kebutaan. Indonesia memegang posisi tertinggi di South East Asia $(1,50 \%)$ dibanding Bangladesh (1\%), India $(0,70 \%)$ dan Thailand $(0,30 \%)$. Jumlah ini akan diperkirakan meningkat $2 x$ lipat pada tahun 2020. Organisasi kesehatan dunia bersama dengan 20 organisasi non pemerintah internasional (Non-Governmental Organization), Asosiasi Profesional, Institusi Kesehatan Mata, meluncurkan Vision 2020 yang bertujuan untuk mengurangi kebutaan pada tahun 2020.
Kegiatan pengabdian kepada masyarakat ini bertujuan untuk diseminasi informasi dan peningkatan pengetahuan masyarakat dan kader dusun Watu tentang penyakit DM dan komplikasi di mata serta melatih para kader agar dapat melakukan pengukuran kadar gula darah.

\section{METODE}

Metode pengabdian masyarakat berupa pendidikan kesehatan dilaksanakan secara online dalam bentuk webinar dengan aplikasi Zoom Meeting. Kegiatan pendidikan kesehatan dimulai dengan pretes kemudian sesi pemaparan materi dan diakhiri sesi postes untuk mengukur tingkat pengetahuan peserta. Kegiatan sesi praktik pengukuran gula darah dilaksanakan secara tatap muka khusus bagi kader Dusun Watu. Sesi praktik didampingi oleh instruktur/trainer kesehatan.

Kegiatan Webinar ini dilaksanakan dalam rangka rangka World Diabetes Day bekerjasama dengan Muhammadiyah Medical Students' Activities (MMSA) KM FKIK UMY berkolaborasi dengan Community Development ARIES kerja sama dengan Dusun Watu, Kecamatan Sedayu, Kabupaten Bantul sebagai desa binaan MMSA. Kegiatan diselenggarakan dalam bentuk webinar Reduce Risk Factor (RESISTOR) dengan tema "Dealing with Diabetes during COVID-19 Pandemic Era"

Pembicara webinar yaitu dr. R. Bowo Pramono Sp.PD -KEMD (K) sebagi ketua PERSADIA, dr. Muhammad Khotibuddin, M.P.H. ahli Kesehatan Gizi Masyarakat, dan dokter spesialis mata (dr. Nur Shania, Sp.M, dr Yunani Setyandriana, Sp. M, dr. Akmad Iklilludin, Sp.M). Kegiatan dipandu oleh Moderator dr. Ika Setyawati, M.Sc dan Yulinda S.C Putri, S.Ked. 
Materi webinar meliputi gambaran umum penyakit Dm (definisi umum, tanda dan gejala, tatalaksana, komplikasi dan pencegahannya. Komplikasi dibahas secara umum di organ tubuh dan secara khusus di organ mata. Komplikasi atau faktor risiko DM terhadap penyakit mata diantaranya adalah glaucoma akibat DM, katarak diabetika, dan retinopati diabetika. Pencegahan dan pengeolaan DM dapat dilakukan dengan cara mengatur pola makan/diit dan olah raga.

Kegiatan webinar diikuti oleh 141 orang secara online melalui aplikasi Zoom Meeting. Kegiatan praktik pemeriksaan kadar gula darah dilaksanakan secara tatap muka di Dusun Watu, Argomulyo, Sedayu, Bantul, Yogyakarta dan dihadiri oleh 6 orang kader posyandu pada tanggal 29 November 2020 .

\section{HASIL DAN PEMBAHASAN}

Kegiatan pengabdian kepada masyarakat oleh dosen Prodi Pendidikan Dokter Universitas Muhammadiyah Yogyakarta ini diawali dengan survey awal terkait permasalahan yang dialami oleh masyarakat dusun Watu. Salah satu masalah yang ada di dusun Watu adalah rendahnya tingkat pengetahuan masyarakat tentang DM dan terbatasnya kemampuan kader dalam melakukan pemeriksaan kadar gula darah.

Diabetes mellitus dalam mayarakat awam dikenal dengan kencing manis merupakan penyakit yang ditandai dengan peningkatan kadar gula darah lebih dari normal. Salah satu dampak buruk dari DM adalah rusaknya sistem organ tubuh termasuk saraf ataupun pembuluh darah (Smeltzer \& Bare, 2008).

Prevalensi DM yang terus meningkat ini perlu dikelola secara efektif untuk memberikan penanganan secara optimal. Pengobatan yang tepat bagi DM dapat menghindari komplikasi (Yuliani et al, 2014). Sehingga salah satu cara untuk mewujudkannya adalah dengan meningkatkan pengetahuan masyarakat dan peran kader posyandu dalam deteksi dini kejadian DM dalam upaya pencegahan prevalensi dan komplikasinya.
Kegiatan ini memiliki sasaran utama yaitu masyarakat dan kader posyandu khususnya dusun Watu. Kegiatan dimulai dengan pretes melalui google form. Webinar dimulai dengan pembukaan oleh Wakil Dekan FKIK UMY kemudian dilanjutkan pemaparan materi oleh para narasumber. Kegiatan di akhiri dengan postes melalui google form.

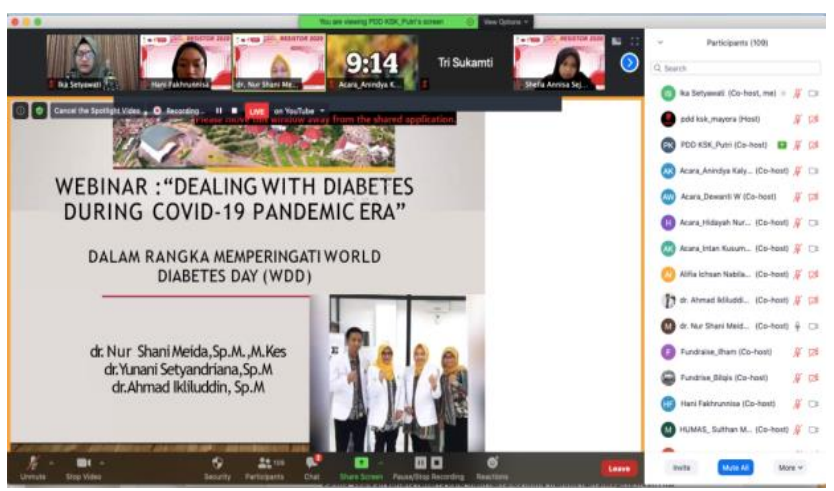

Gambar 1. Webinar dengan aplikasi Zoom Meeting

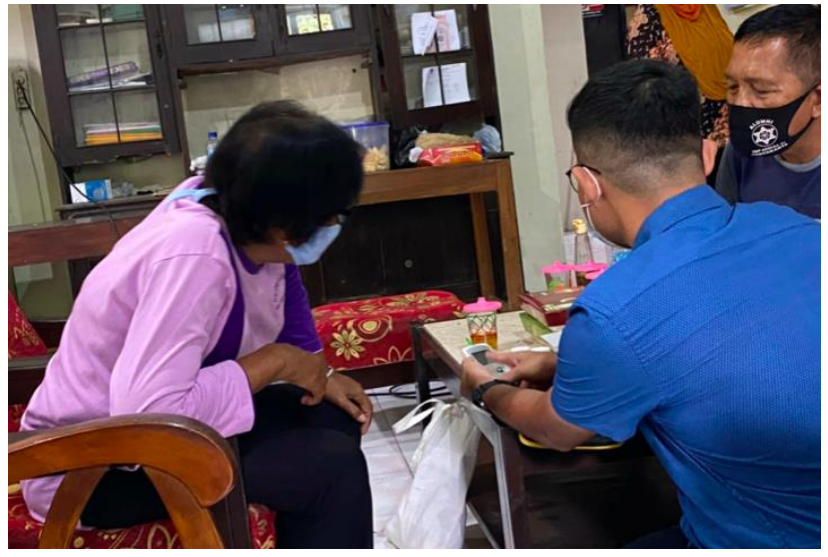

Gambar 2. Pelatihan Pengukuran kadar Gula Darah

Total peserta yang mengikuti kegiatan sebanyak 141 peserta. Jumlah yang mengerjakan pretes sebanyak 136 peserta, yang mengerjakan postes sebanyak 114 peserta. Jumlah peserta yang mengerjakan pretes dan postes sebanyak 103 peserta.

Tingkat pengetahuan peserta tentang DM mengalami peningkatan dari nilai pretes dibandingkan nilai postes. Rerata nilai postes $(89,90)$ lebih tinggi dibandingkan rerata nilai pretes $(77,41)$. Terdapat peningkatan nilai 
Nur Shani Meida, Yunani Setyandriana, Ika Setyawati, Refi Nurcholis

Upaya Preventif Tingkat Keparahan Penyakit Diabetes Mellitus dengan Diet dan Olahraga serta Mengenali Komplikasi Awal di Mata

postes dibandingkan nilai pretes $(92,32 \%)$ yang dapat dilihat pada tabel 1 .

Tabel 1. Rerata Nilai Pretes dan Postes

\begin{tabular}{ll}
\hline Kegiatan & Nilai \\
\hline Pretes & 77,41 \\
Postes & 89,90 \\
\hline
\end{tabular}

Seluruh kader dapat melakukan pengukuran kadar gula darah dengan baik dengan alat glukometer stik. Kemampuan pengukuran kadar gula darah tersebut dinilai berdasarkan pengamatan langsung oleh trainer. Seluruh kader dapat melakukan pemeriksaan kadar gula darah (100\%).

Pelatihan cara pengukuran kadar gula darah menggunakan glukometer stik diawali dengan penjelasan dan demonstrasi. Para kader melakukan roleplay (praktik) cara mengukur kadar gula darah dengan pengawasan oleh trainer.

Menurut Depkes tahun 2009, terdapat beberapa macam pemeriksaan kadar gula darah yaitu (1) kadar gula darah sewaktu; (2) kadar gula darah puasa dan 2 jam setelah makan; (3) pemeriksaan penyaring: toleransi glukosa terganggu/TGT, glukosa darah puasa terganggu/GDPT, dan tes toleransi glukosa oral/TTGO.

Pada pelatihan ini, cara pemeriksaan kadar gula darah yang dipraktikkan adalah cara pemeriksaan kadar gula darah sewaktu. Hal ini dipilih karena merupakan cara paling mudah bagi masyarakat dalam memantau kadar gula darah secara rutin untuk mencegah komplikasi akibat DM.

\section{SIMPULAN}

Terdapat peningkatan pengetahuan masyarakat tentang DM dan pencegahan komplikasi di mata $(92,32 \%)$ serta seluruh kader dapat melakukan pengukuran kadar gula darah secara mandiri (100\%).

Perlu diadakan follow up kegiatan pengabdian untuk mengetahui peran kader dalam deteksi dini kasus Diabetes Mellitus.

\section{UCAPAN TERIMA KASIH}

$\begin{array}{ccc} & \text { Terima kasih kami } & \text { ucapkan kepada } \\ \text { LP3M } & \text { Universitas } & \text { Muhammadiyah }\end{array}$ Yogyakarta yang telah memberikan hibah dana Pengabdian Kepada Mayarakat.

Ucapan terima kasih diberikan juga kepada Kepala Dukuh Watu, Dekan FKIK UMY dan MMSA yang telah memfasilitasi sehingga kegiatan ini dapat berlangsung.

\section{DAFTAR PUSTAKA}

Departemen Kesehatan RI. 2009. Profil kesehatan Indonesia 2007. Jakarta: Depkes RI Jakarta. https://www.kemkes.go.id/resources/do wnload/pusdatin/profil-kesehatanindonesia/profil-kesehatan-indonesia2008.pdf

Khaled Ahmad., et al. (2010). Type 2 Diabates and Vascular Complication: A Pathophysiologic View. Biomedical Research.21 (2): 147-155.

Perkeni (2011). Konsensus Pengendalian dan Pencegahan Diabetes Mellitus Tipe2 di Indonesia 2011. Pengurus Besar Perkumpulan Endokrinologi Indonesia, pp: 6-8, 14-30.

Riset Kesehatan Dasar (Riskesdas) (2018). Badan Penelitian dan Pengembangan Kesehatan Kementerian RI tahun 2018. https://kesmas.kemkes.go.id/assets/uplo ad/dir_519d41d8cd98f00/files/Hasilriskesdas-2018_1274.pdf

Setiati, S., Alwi, I., Sudoyo, A.W., \& Simadibrata, M., 2017. Buku Ajar Ilmu Penyakit Dalam.

Smeltzer \& Bare. (2008). Buku Ajar Keperawatan Medikal Bedah Brunner \& Suddarth/ editor, Suzzane C. Smeltzer, Brenda G. Bare; alih bahasa, Agung Waluyo, dkk. Jakarta: EGC.

Vasudev Anand, P., Sridhar, G. (2018). A Clinical Study of the Ocular Complications of Diabetes Mellitus. Journal of Dental and Medical 
Sciences. Volume 17, Issue 10 Ver 3 (October.2 2018), PP 45-49.

Vieira-Potter J V, karamichos D., et al. (2016). Ocular Complications of Diabetes and Therapeutic Approaches. BioMed research International. Volume 2016, Article ID 380157`0, 14 pages.

Zhao YX, Chen XW. Diabetes and risk of glaucoma: systematic review and a Meta-analysis of prospective cohort studies. Int $J$ Ophthalmol 2017;1099):1430-1435.

Zhou Minwen., Wang Wei., et al. (2014). Diabetes Mellitus as a Risk Factor for Open-Angle Glaucoma: A Systemic Review and Meta-Analysis. www.plosone.org. Volume 9, Issue 8, e102972.

World Health Organization. 2007. Diabetes. http://www.who.int/topics/diabetes_ mellitus/en/ 